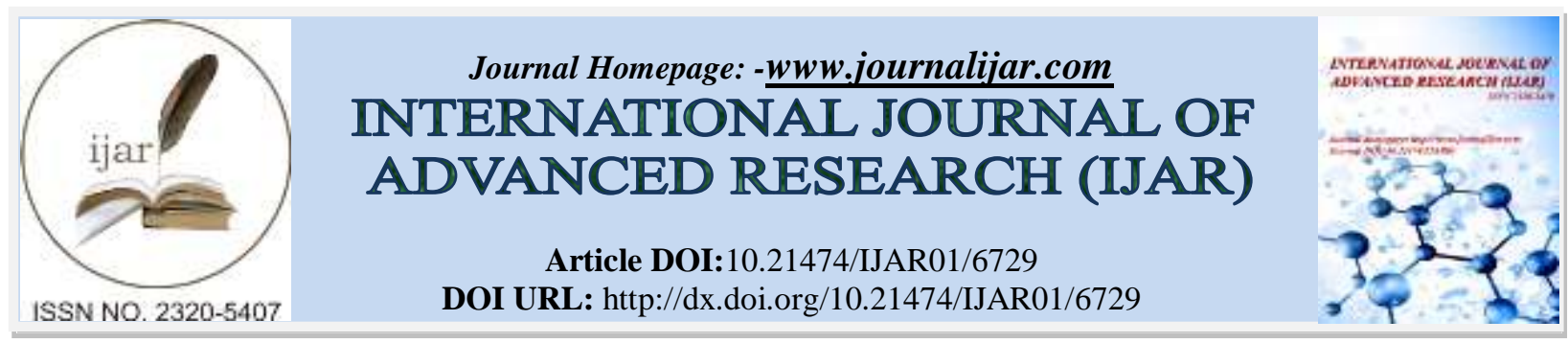

RESEARCH ARTICLE

\title{
HYBRID METHOD IN THE RELIABILITY ALLOCATION IN AN INDUSTRY-A REVIEW.
}

Sunday A. Afolalu, Ikechi V. Ihebom, Remilekun R. Elewa,Samuel U. Ayuba and Kehinde Oluyemi. Mechanical Engineering Department, Covenant University, Ota. Ogun-State, Nigeria.

\section{Manuscript Info}

(..........................

Manuscript History

Received: 12 January 2018

Final Accepted: 14 February 2018

Published: March 2018

Keywords:-

Reliability Allocation, Hybrid method,

Criticality failure rate.

\section{Abstract}

A system`s reliability during the early stage of design is an important issue for consideration. For any engineering system to be of standard it must meet certain reliability goals. These reliability goals can be achieved by assigning reliability requirements of individuals' subsystem to obtain complete system reliability. These reliability allocation to be considered based on engineering factors appear more practical functional and crucial at the early stage of design and development of items.

In this paper we shall be considering the factors of influence approach under the hybrid method. These factors of influence affecting system reliability are complexity/time, the environment, cost, state-of-the-art and criticality of failure.

This method aims at exposing each factor of influence and how each affects the reliability of overall system if not properly taken into consideration at various industries.

Copy Right, IJAR, 2018,. All rights reserved.

\section{Introduction:-}

The reliability of any system is most crucial and cannot be over-emphasized as lives and property depends in the satisfactory functionality of any system over specified conditions and period of time.

The value of reliability depends on the reliability on both the reliability of a component and its corresponding position in the system. Reliability allocation is a decisive step in product design and development in assigning requirements to individual subsystems. These requirements are obtainable and agreed upon by each design group at various level and location. For a system to be designed for a targeted reliability, a reliability goal must be set putting in consideration its system`s behaviour, failure effect and order of improvement (Yadav, 2014).

Other importance for setting reliability goals are to map out improvement avenues on the basics of real potential or crucial information for the reliability improvement. The focus of reliability allocation is to allocate the target reliability to be equal to all the subsystem or components. (Ebeling, 2008).

Reliability Allocation is a tactical task during system design and development process of any engineering system. Due to its delicate nature in application at the early stage of the design some factors have to put into check in order to obtain the specified target level of reliability desired. This brings about the implementation of adequate reliability allocation method where the target reliability allocation method where the target reliability system is carefully allocated its constituent subsystem appropriately.(Sriramdas, 2014). Kim et al (2013), proposed a method that 
assigns lower reliability goals to a subsystem already having lower failure frequency. This proportion shows that the current level of reliability is greater than the assigned reliability target. This occurs as a result of regular severity rating over failure frequency in the model.

Karmiol (2007) postulated the historical information to derive reliability allocation weight. The factors considered by karmiol are operating time, state-of-the- art, subsystem intricacy, and criticality. Bracha, 2011 has similar factors for consideration to obtain reliability weight; the four factors considered by Bracha are state-of-the-art, system complexity, operating time and the environmental conditions. Another method called ARINC was used to obtain reliability allocation weight by providing quantitative information for obtaining the allocating weights.

Richard and Thomas (2012) established target reliability to pursuit practical method in improving reliability components. In this approach he analyzed the affiliation of a product components quality through warranty cost. He postulated that components that fail frequently or have warranty expenses or both will have a corresponding higher warranty burden .His work was to improve reliability allocation by reduction of failure rate of each subsystem in proportion to the relative fraction of warranty cost due to that subsystem. Recent works were carried out on an approach for reliability allocation considering failure analysis generated data from warranty data. This method made use of criticality related information as determinant for reliability allocation and also failure frequency and its occurrence rating is captured in the model follows linearity assumption (Afolalu et al., 2017)

Kuo and Prasad (2013) prepared an overview of the method developed to be efficient in calculating various reliability issues. Yadav, (2014) proposed to capture product behaviour through three dimensional analysis and dependency of a complex functionality in a physical system. Itabashi and Yadav (2014) used FMEA criticality analysis for reliability allocation. The multiplication of these occurrence and severe rate for the calculation of the criticality is based on linearity assumptions. In this postulation, assigning system reliability target level to subsystems in proportion of allocating weights, there must be appropriate assigning of lower reliability target to few subsystems rather than current level reliability.

\section{State -of- the-art:-}

This deal with the length of time a working system has lasted for and its present performance considered in determining further improvement to be made on a component even if the reliability is appropriated lower than desired. For components of higher degree of state-of-the-art the greater the possibility of such item or component to have undergone series of failure analysis or corrective maintenance activities for a length of time (Yadav 2014) but items with initial high reliabilities can be further improved economically. In order to obtain higher degree of stateof-the-art improvement, there are a lot of subsystems selected. So the higher the state-of-the-art the higher the reliability and hence the lower the failure rate.

\section{Maintenance:-}

A subsystem or parts where regularly maintenance is carried out it monitor the overall operating of the overall system to avoid unexpected breakdown or failure during the overall functioning of the entire system. The higher the rate of maintenance the higher the availability of that system when demanded (Adetunji et al., 2015). Thus the higher the availability the greater possibility for apportioning relatively lowers reliability corresponding to higher failure rate.

\section{Criticality of Failure:-}

This is a degree of failure that occurs in any system whose failure could threaten human life, the system`s environment or organizational existence if it is not in a satisfactory good condition. Every system has its own failure criticality where the failure of such components or part spells disaster and danger to the overall system (Abioye et al., 2017). The factor of influence method is based on the notion that the factors affect the system reliability for example the failure of some other auxiliary parts or component in an airplane may not be crucial or critical is the failure of Engine (Dhilon 2006). A functional critical subsystem should be allocated a reliability target. The proper placement of system is allocated a reliability target. The proper placements of system to their relative criticality of failure are based on two parameters: the failure effect of the functional group of system, frequency of failure (Orisanmi et al., 2017). 


\section{Complexity and Time factor:-}

This relates the amount of subsystems parts and the corresponding relative operational time or working time during the functional period of an overall system when considering the reliability allocation a minimal amount of subsystem should be viewed and it must be simple as possible to detect a failure that may occur in the overall system reliability. In allocating the number of subsystems desired, the appropriate operating time for the system is determined and is lower than the overall mission time of the entire system. In this factor of complexity it is not easy to achieve the target reliability for a subsystem with greater complexity. Complexity has a huge impact on reliability allocation. The higher the complexity, the higher the failure rate of the subsystem. (Sriramadas and Yadav 2014)

\section{Cost:-}

Cost is important factor to be considered for system reliability. For a larger system there is a high increment in cost for an improved reliability. So the higher the reliability allocated to the components the lower the failure rate and the higher the maintenance cost. For a subsystem to be costly a relatively lower value of reliability is expected to be allocated. (Sriramadas, 2014). The demonstration of a high value reliability is of a reduced cost when viewed at the long run, The higher the reliability improvement cost the lower the apportioned target (Salawu et al., 2018)

\section{Hybrid method:-}

This method considers the combination of 2 approaches which are similar familiar systems method and the factors of influence method. The basic of each approach is to incorporate benefit of reliability allocation on system (Dhillon 2006). The foundation for similar familiar system method is designer`s familiarity with similar systems and subsystem especially during allocation process. During this process of allocation of an item used failure data collected from similar subsystem and system from various sources. The demerit in this approach is to conclude that life cycle cost and product reliability of similar design are the same. This method has not been frequently applied in engineering like the other like fuzzy method, ARINC etc.

\section{The Application of Hybrid Method in Concurrent Engineering Environment:-}

Concurrent Engineering is a systematic approach to the concurrent design of products and their related processes, including manufacture and support. Concurrent Engineering is a method of product design and development where the stages of production run simultaneously instead of after each other (Oyinbo et al., 2015). This environment time to market is affected and the development of product as well; thereby causing improved productivity and at minimal cost. Concurrent Engineering also known as simultaneous Engineering has a long term benefit. This method looks into possible problems that may arise from selection of processes and suppliers in concurrent Engineering towards product development (Bopana 1997). The early design stage processes and suppliers is challenging due to not enough actual evaluating parameters.

This method helps in decision making model by sampling both quantitative and qualitative method to obtain the best option of processes and suppliers to be implemented in Concurrent Engineering Environment (Shahrokhi 2011). To help select processes and suppliers best for this field some parameters like cost, quality of design, operating time has to be considered. This model allocates specific amount of products to be ordered to each supplier with a degree of buyers` demand capacity and supplier`s capacity to be deliberated. In Concurrent Engineering the safety of product is the most paramount factor, therefore for each component the quality of the components/ parts, proposed assembly process assembly cost, and time of assembly are information or data to be processed (Benard 2011).

\section{Conclusion:-}

The hybrid method is very useful in existing systems where the objectives is to identify and further improve upon product reliability and design and development processes thereby increasing reliability goals for components and subsystem it provides a more realistic and effective reliability allocation approach considering potential for improvement. The consideration of non-linear phenomena in severity rating and failure rate to capture potential for reliability improvement has significantly improved the effectiveness of this method over other methods. The reliability improvement target allocation method ensures each subsystem gets improvement target assigned in proportion of potential for improvement as well as exposes technological difficulty in achieving improvement goals when negative failure rate target is assigned. This paper proposes a realistic reliability allocation approach by taking into account the potential for reliability improvement, improvement impact on failure severity, and the degree of difficulty associated with reliability improvement efforts required to achieve given reliability goals. There is a common synchrony within design community that the further improvement in reliability for a highly reliable system 
requires more intense efforts and hence costs more than benefits resulting through reliability improvement as compared to system with higher failure rate.

\section{References:-}

1. Zhao Guangyan, Qin Tong, Sun Yunfeng (2011), the method of mission reliability allocated for complex system based on simulation. Vol 2 Edition 5.

2. B.S Dhilion (2006), Maintainability, maintenance and reliability for Engineers. CRC press Taylor \& Francis group, FL 33487-2742 Ottawa Ontario.

3. Aggarwal, k.k (2007) Reliability Engineering Netherlands: klular Academic publishers.

4. Kyunmee, O.K, Yoonjung Y. Ming J.Z (2013). A new reliability allocation weight for reducing the occurrence of severe failure effects, Reliability Engineering and system safety 117, 81-88

5. Alven WH. 1964.Reliability Engineering prepared by ARINC Research Corporation. Englewood Cliffs, NJ: Prentice Hall;

6. Department of Defense of USA. (1998)MIL-HDBK-338B. Electronic design reliability handbook,

7. Kececioglu D.1991 Reliability engineering handbook, vol. 2. Prentice Hall;

8. Advisory Group of Reliability of Electronic Equipment (AGREE). 1957. Reliability of military electronic equipment. Office of the Assistant Secretary of Defense Research and Engineering: Washington, DC;

9. Mettas, A. 2000. Reliability allocation and optimization for complex systems. Proceedings of the annual Maintainability and Reliability Symposium, Los Angles: pp.216-221.29

10. Nakagawa, Y. and Nakashima, K. (1977). A heuristic method for determining reliability allocation. IEEE Transactions on Reliability. Vol. 26: pp.156-161

11. Abioye, A. A., Atanda, P. O., Abioye, O. P., Afolalu, S. A., \& Dirisu, J. O. (2017). Microstructural Characterization and Some Mechanical Behaviour of Low Manganese Austempered Ferritic Ductile Iron. International Journal of Applied Engineering Research, 12(23), 14435-14441

12. Kuo, W. and Prasad, V.R. (2000). An annotated overview of system reliability optimization. IEEE Transactions on Reliability Engineering. Vol. 49: pp.176-187

13. Wang Y, Yam RCM, Zuo MJ, Tse P. (2000). A comprehensive reliability allocation method for design of CNC lathes, Reliability Engineering and System Safety. 72: 247-52.

14. Yadav O.P, Singh, N. and Goel P.S. (2006). Reliability demonstration test planning: a three-dimensional consideration, Reliability Engineering and System Safety; 91:882-93.

15. Itabashi-Campbell R, Yadav O. 2008. Gauging quality and reliability assurance efforts in product development process. International Journal of Process Management \& Benchmarking, January; 2(3):221-233

16. Kyungmee O. Kim, Yoonjung Yang, Ming J. Zuo. 2013. A new reliability weight for reducing the occurrence of severe failure effects, Reliability Engineering and System Safety. 117:81-88.

17. Bracha VJ. (2004)The methods of reliability engineering, Machine Design; 7:70-76.

18. Kuo W, Prasad VR, Tillman FA, Hwang CL.( 2001), Optimal reliability design. Cambridge University Press;

19. Oyinbo, S. T., Ikumapayi, O. M., Ajiboye, J. S., \& Afolalu, S. A. (2015). Numerical Simulation of Axisymmetric and Asymmetric Extrusion Process Using Finite Element Method. International Journal of Scientific \& Engineering Research, 6(6), 1246-1259

20. Thomas, M. U., \& Richard, J. P. (2006). Warranty-based method for establishing reliability improvement targets. IIE Transactions, 38(12), 1049-1058.

21. Saadi S, Djebabra M, Boubaker L. 2011; Proposal for a new allocation method of environmental goals applied to an Algerian cement factory. Management of Environmental Quality: An International Journal. 22:581-594.

22. Yadav O.P (2007). System reliability allocation methodology based on three-dimensional analyses, International Journal of Reliability and Safety; edition 1:360-75.

23. Afolalu, S. A., Salawu, E. Y., Okokpujie, I. P., Abioye, A. A., Abioye, O. P., Udo, M., \& Ikumapayi, O. M. (2017). Experimental Analysis of the Wear Properties of Carburized HSS (ASTM A600) Cutting Tool. International Journal of Applied Engineering Research, 12(19), 8995-9003.

24. Salawu, E.Y., Okokpujie, I.P., Afolalu, S.A., Ajayi, O.O. and Azeta, J., 2018. INVESTIGATION OF PRODUCTION OUTPUT FOR IMPROVEMENT. International Journal of Mechanical and Production Engineering Research and Development, 8(1), pp.915-922

25. Orisanmi, B. O., Afolalu, S. A., Adetunji, O. R., Salawu, E. Y., \& Okokpujie, I. P. (2017). Cost of Corrosion of Metallic Products in Federal University of Agriculture, Abeokuta. International Journal of Applied Engineering Research, 12(24), 14141-14147

26. Adetunji O.R., Adegbola A.O., \& Afolalu, S.A. (2015). Comparative Study of Case-Hardening and Water-Quenching of Mild Steel Rod on Its Mechanical Properties.International Journal of Advance Research, 3(6)1-9. 